\title{
MEMÓRIAS DISCURSIVAS, LÍNGUAS E IDENTIDADES SÓCIO-CULTURAIS
}

\author{
Silvana Serrani
}

RESUMO: In this article, I discuss language learning from a discursive point of view. Thus, I examine the notions of socio-cultural identity, subjective identification and discursive formation. In the first part of the text, arguments against a homogeneous view of identity result from considering identification processes as components of the heterogeneity of subject and language. In the second part of the article, I discuss the implications for the language learning process of real interdependence of subject, language and discourse. In order to clarify the comprehension of how and why words do not signify in themselves, I present an illustration of metaphorical and metonimic processes in language acquisition. I also comment an implementation of the notion of discursive formation in a predidactic analysis of three texts of editorial discourse in journals of science. To conclude, I insist on the importance of going beyond the linguistic system and the level of intention when considering the implicit dimension in language. I also criticize normative standards and myths of omnipotence in educational projects concerning second languages.

PALAVRAS-CHAVE: identidade, língua estrangeira, memórias discursivas, identificações subjetivas, processos metafóricos, processos metonímicos, formação discursiva

Silvana Mabel Serrani de Infante é professora da Universidade Estadual de Campinas 


\section{INTRODUÇÃO}

Neste texto, discutirei a concepção do processo de aprendizagem de línguas, à luz da teoria do discurso. Para tanto, em um primeiro momento, tratarei a relação desse processo com a constituição heterogênea das identidades sócio-culturais, considerando as identificações do sujeito do discurso. Em um segundo momento, destacarei a importância de se conceber a língua sempre na inter-relação sujeito-língua-discurso, em práticas educacionais.

A produção em línguas não maternas, o bilingüismo e o plurilingüismo são fenômenos de grande interesse para os estudos gerais sobre a natureza e o funcionamento da linguage $\mathrm{m}^{1}$. No caso específico dos estudos do discurso, a enunciação em línguas estrangeiras é um campo frutífero para desenvolvimentos teórico-metodológicos, especialmente aqueles ligados à heterogeneidade da linguagem e do sujeito. Concomitantemente, a abordagem desses fenômenos na perspectiva do discurso leva a consequiências para práticas de uso ou aprendizagem de línguas. No contexto educativo, essas consequiências dizem respeito a três âmbitos: a) concepções teóricas fundamentais; b) decisões de política educativo-cultural; e c) atividades concretas em salas de aula. Esses âmbitos são interdependentes e de consideração indispensável em qualquer projeto pedagógico consistente ${ }^{2}$. Neste texto o foco está no primeiro desses âmbitos.

\section{Memórias Discursivas, Identidades Sócio-culturais e Identificações Subjetivas}

Enunciar em línguas estrangeiras talvez seja uma das experiências mais visivelmente mobilizadoras de questões identitárias no sujeito. Em situações imigratórias isso é mais evidente; mas o questionamento identitário está também presente em situações tais como aulas de língua estrangeira no próprio país do aprendiz. A experiência é mobilizadora, especialmente, pelo seu caráter contraditório: por um lado, a relação com outras línguas e culturas é uma experiência em direção ao novo mas, pelo mesmo movi-

${ }^{1}$ Jakobson, por exemplo, considerava que o bilingüismo é o problema fundamental da Lingüística. Cf. Jakobson, Essais de linguistique générale, 1969, p. 35.

${ }_{2}^{2}$ O estudioso canadense David Stern (1989) salienta a importância, em todo projeto do campo educativo, de explicitação das opções feitas em cada um desses três âmbitos. Isso vale tanto para projetos de implementação prática de programas, currículos, cursos etc., como para projetos de pesquisa nesse campo. Senão, como ele bem formulou, corre-se o risco de "ver-se a árvore mas não o bosque". 
mento, são solicitadas as bases mais antigas da estruturação subjetiva, isto é, daquilo que de uma história, que sempre é social, sedimenta na singularidade do sujeito ${ }^{3}$. Assim, a experiência mobilizadora se dirige, também, em direção à língua materna, entendida não apenas como a língua nacional de origem, mas como aquela que teceu o inconsciente e as memórias discursivas que constituem a denominada "identidade sócio-cultural" do sujeito. Essas memórias são constitutivas porque já antes de falar, todo sujeito está imerso em um mundo de dizeres, no qual há sempre interpretações (implícitas ou denegadas) sobre a criança e seu sentir, sobre o mundo a sua volta, sobre expectativas em relação a ele e assim por diante. Uma característica da espécie humana é a de os seres recém-nascidos ou novos não sobreviverem sem cuidados prolongados dos mais velhos. Nessa convivência, o ser humano está imerso em inúmeros discursos que o interpelam, adquire a linguagem e constitui os alicerces de sua subjetividade. As memórias discursivas são aquilo que está inscrito no sujeito juntamente com/nas palavras da língua materna. E é isso que o encontro com novas línguas e culturas questionará, mobilizará, perturbará.

Falar outras línguas nos remete nitidamente ao que Todorov aponta como "nós e os outros". A língua nacional e a nação são conceitos diretamente ligados ao de identidade sócio-cultural. Para caracterizá-los, o autor lembra que a nação pode ser entendida seguindo os modelos da raça ou do contrato. No primeiro, considera-se a identidade diretamente vinculada a uma comunidade "de sangue", na qual se nasce e se permanece sempre; no segundo, pertence-se a uma nação por um ato de vontade, por um compromisso de viver adotando regras e projetando um porvir comum. Para superar ambos os modelos, Todorov propõe um terceiro que relaciona nação a cultura. Esta última, por um lado, é anterior ao indivíduo (modelo da raça) mas, por outro, é também adquirida (visão do contrato). No entender desse autor, para adquirir uma cultura é preciso um domínio da língua, uma familiarização com a história do país, com sua paisagem e com os costumes de seu povo de origem, regidos por mil códigos invisíveis ${ }^{4}$. Ainda que esta proposta comporte um certo dinamismo conceitual, as culturas e as identidades, na perspectiva de Todorov, parecem entidades bem configuradas. Entretanto, existe uma pluralidade real das identidades no cotidiano que leva a questionar esse tipo de visão.

O termo 'identidade', em sua concepção tradicional, sugere uma idéia de unidade e estabilidade. Ela é conflitante com o decentramento introduzido pela descoberta do inconsciente, no estudo da subjetividade, e

${ }^{3}$ Cf. Revuz, 1998; Calligaris,1997.

${ }^{4}$ Cf. Todorov, 1988, p. 424. 
pela concepção polifônica e heterogênea da linguagem. A consideração da divisão inconsciente/consciente separa o sujeito de parte dele "mesmo". Uma locução, vista como discurso, excede a unicidade da seqüência linear e da intenção do locutor. É insuficiente limitar a dimensão do implícito a um "querer dizer" da ordem do intencional. O dito vai sempre além da intenção assumida ou negada. É dito sempre mais do que se sabe, não se sabe totalmente o que se está dizendo, pois um algo a mais da ordem do inconsciente e da ideologia é sempre dito além do formulado ou, também, fala-se para "não dizer nada" ${ }^{5}$.

Tomar a palavra não é apenas o uso do "instrumento língua" para transmitir "intenções de comunicação". Quando se toma a palavra, tomase um lugar enunciativo, que diz respeito a posições enunciativas e a relações de poder nas diversas instituições sociais (públicas ou privadas) em que todo discurso acontece ${ }^{6}$. No limiar da consciência atuam representações que os interlocutores se fazem da enunciação em um determinado contexto. Isso foi bem mostrado por Pêcheux ao explicitar as formações imaginárias do acontecimento discursivo, exemplificadas por perguntas tais como: "Quem sou eu para dizer isto a ele? Quem é ele para me falar dessa maneira? Onde estamos para falar assim?" Qual imagem ele tem de mim em relação a isso, para me falar sobre o assunto de tal forma?", e assim por diante ${ }^{7}$. As «respostas» a essas perguntas implícitas se materializarão, também implicitamente, nas produções verbais, cujos conteúdos poderão ser os mais diversos. Elas projetarão no discurso não apenas a individualidade dos interlocutores e o contexto em seus traços mais visíveis ou situacionais, mas também, e sobretudo, a representação social desses traços na simbólica social, conforme as posições ideológicas dos sujeitos envolvidos.

Ao conceber o processo de enunciar em segundas línguas como parte do processo discursivo fundamental de tomada da palavra, focalizam-se os elos sociais dos quais fazem parte as identificações subjetivas. A noção de identificação é estudada especialmente no campo da Psicanálise. Enquanto a identidade pode ser entendida como representação do ser, a identificação enfatiza a referência ao dizer ${ }^{8}$. Trata-se dos elos sociais, materializados em nexos de linguagem, em que por identificação se relacionam posições subjetivas na produção-compreensão discursiva. Mediante as identificações o sujeito adquire, não sua unidade, mas sua singularida-

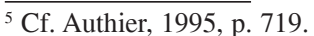

${ }^{6}$ Para estudos detalhados sobre a natureza e o funcionamento do discurso, ver Orlandi, 1983 e 1996.

${ }^{7}$ Cf. Pêcheux, 1990.

${ }^{8}$ Ver Souza, 1994 e Bonnet, 1996. 
de. A partir dos estudos de Freud são distinguidos três tipos de identificação: a imaginária, a simbólica e a fantasística. Esta última é também chamada de identificação histérica e diz respeito à adoção mimética de sintomas neuróticos de uma pessoa a partir das falas ou ações de uma outra. Esse tipo de identificação é muito relevante nos estudos vinculados à clínica. Para os objetivos de compreensão do processo de enunciação em línguas não maternas, interessam especialmente os dois primeiros tipos. $\mathrm{Na}$ identificação imaginária os componentes são a imagem e o eu. Nessa apreensão da relação enunciador-realidade, o mundo não se entende como composto somente de coisas e seres, mas também de imagens. O eu imaginário se define como uma estratificação incessante de imagens continuamente inscritas em nosso inconsciente. Mas o eu só se identifica seletivamente com as imagens em que, de algum modo, se reconhece ${ }^{9}$. Na identificação simbólica, não se trata do eu-falante, mas do sujeito do inconsciente, que é uma instância abstrata e, finalmente, não individual. A identificação simbólica, na concepção freudiana, se situa na existência de um traço que se repete e que liga em conjunto entes amados, desejados e perdidos do sujeito. Mas esse outro, objeto de identificação, não é, de fato, o objeto, a pessoa, o gesto, a formulação, etc. externo, percebido conscientemente. $\mathrm{O}$ processo de identificação acontece, propriamente, entre duas instâncias inconscientes do sujeito. Mannoni (1994, p. 196) observa que "uma identificação é uma captura. Aquele que se identifica talvez creia que está capturando o outro, mas é ele quem é capturado". E o autor acrescenta: "para não ser capturado, há uma coisa que se pode fazer: em vez de identificarse, pode-se fazer uma imitação ou uma macaquice."

Dada a pluralidade de memórias, de gêneros discursivos e de contextos, é praticamente impossível fazer um inventário exaustivo de identificações. Entretanto, elas podem ser analisadas, de modo particular, ao abordar a construção de identidades sócio-culturais em determinados discursos e domínios de saber, em contextos sócio-históricos específicos. Os estudos do discurso procuram contribuir nesse sentido. As descrições discursivas da linguagem disponíveis são quantitativamente menores do que as descrições de sistemas lingüísticos. Mas, seu número não é escasso em revistas especializadas. O que parece ser limitada ainda é a incidência desses estudos no campo educativo e, especialmente, na área de ensinoaprendizagem de línguas estrangeiras. Muitas vezes, aponta-se como causa a falta de materiais didáticos adequados. Essa falta pode existir, porém para implementar esse tipo de trabalho antes do que materiais didáticos novos, é preciso formar professores e agentes pedagógicos mais familiari-

${ }^{9}$ Cf. Nasio, 1995, p. 116. 
zados com os processos subjetivos, identitários e ideológicos envolvidos. Para tanto, maior ênfase em procedimentos básicos das ciências sociais e em análise do discurso parece recomendável para que a língua não seja concebida desvinculada dos processos histórico-discursivos nos quais sempre se realiza. Dessa forma, procura-se, nos termos de Mannoni, propiciar no sujeito identificações, e não "macaquices".

Independentemente das características particulares de encontro com uma língua não materna, um fator a considerar sempre é o de o sujeito estar ou não pronto para experiências de estranhamento. E aqui se trata tanto do estranhamento surgido do confronto com outras línguas e culturas quanto ao próprio estranhamento ${ }^{10}$, ou seja a relação do sujeito com as heterogeneidades e contradições que o habitam. Por isso, na formação docente, talvez seja preciso relativizar a importância das chamadas «estratégias de aprendizagem»e preocupar-se em formar agentes pedagógicos preparados para lidar com estratégias inconscientes de não aprendizagem. Com efeito, não é raro que mesmo que o aluno afirme veementemente que quer aprender uma determinada língua, dada a complexidade dos processos apontados, haja indícios que apontem na direção contrária. De todas formas, a transformação de padrões enunciativo-discursivos e comportamentais é um fenômeno muito complexo e ligado às identificações que possibilitam a construção de representações identitárias. Assim, vale a pena se interrogar sobre o modo de sua inclusão entre os objetivos do ensino de línguas estrangeiras. Dois exemplos de Jorden e Saville Troike (1992) ${ }^{11}$ contribuem para essa reflexão. O primeiro deles trata da resposta dada por um aluno japonês de inglês, nos Estados Unidos. Quando solicitado a se apresentar pelo seu primeiro nome, o estudante disse "é para me chamar de Sr. Tanaka". O professor manifesta desapontamento e ao solicitar orientação, Jorden informa que a mesma foi a de aceitar a posição do aluno, mas fazendo, também, a advertência sobre como os americanos iriam reagir a alguém que dissesse "não me chame pelo meu primeiro nome, dirija-se a mim somente como Sr. Tanaka". A atenção em relação a preponderâncias enunciativas em determinadas sociedades é um avanço relevante mas, na perspectiva do discurso, seria questionável, nessa resposta, a generalização "os americanos". Ela parece implicitar uma homogeneidade que não se sustenta. Relativizar afirmações como essas e discutir como "muitos americanos" talvez pudessem reagir em determina-

${ }^{10}$ Cf. Kristeva, 1991.

${ }^{11}$ Saville, Troike, M. "Cultural maintenance in "vanishing" Englishes", in Kramsch and McConnell-Ginet (eds.), 1992, p. 280.

Jorden, E. "Culture in the Japanese language classroom : A pedagogical paradox", in Kramsch and McConnell-Ginet (eds.) 1992, apud. Kramsch, 1996. 
dos contextos pode ser um caminho de mobilizar processos identificatórios ou desidentificatórios. O segundo exemplo diz respeito a uma aluna japonesa que se inclinava muito ao cumprimentar seus professores americanos. Quando advertida para não fazer essas reverências nos Estados Unidos, ela respondeu: "eu sei que os americanos não se inclinam, mas essa é a minha cultura, e se eu não faço isso, não estou sendo respeitosa ${ }^{12}$." Não se trata de um mundo dado, geral, codificado em diferentes línguas. A produção de sentidos pela linguagem verbal e não verbal está intimamente ligada à constituição subjetiva e à representação identitária. O conflito observado nessas ilustrações de línguas e culturas nitidamente distantes, constata-se, também, no caso de línguas vizinhas e de culturas aparentemente próximas. As características do conflito são, às vezes, mais sutis, entretanto não por isso deixam de ter importância e consequiências significativas. Por exemplo, em análises da construção de polidez em discursos em espanhol riopratense e português brasileiro paulista, comprovei que os implícitos decorrentes da diferente estruturação textual (por exemplo para a construção discursiva dos sentidos de queixa ou reclamação) produzem mal-entendidos semânticos, com conseqüências não desprezíveis na sociabilidade ${ }^{13}$.

A seguir, discutirei a importância de não desvincular a língua da inter-relação sujeito-língua-discurso, ao conceber o processo de aprendizagem de línguas em contexto educativo.

\section{Além do Sistema Lingüístico: processos metafóricos, metonímicos e formações discursivas}

Em realizações diversas do contexto de ensino-aprendizagem de línguas, constatam-se com freqüência paradoxos e situações aparentemente inexplicáveis. Como é que pessoas comprovadamente muito inteligentes, que dizem querer muito falar uma determinada língua estrangeira, assistem a numerosas aulas, estudam e conhecem múltiplas regras gramaticais e uma quantidade de léxico considerável, mas mesmo assim, muitas vezes, não conseguem se expressar significativamente na nova língua? Ou, o que é "aquilo" que, em algumas ocasiões, faz com que um determinado aprendiz de língua estrangeira, quando ninguém espera, "de repente", deslanche e comece a se expressar melhor na nova língua? Diferentes abordagens de ensino-aprendizagem de línguas têm dado, em épocas diversas, respostas singulares para questões como essas. Nos últimos anos, por exemplo, em enfoques denominados "comunicativos", tem sido proposto que o

\footnotetext{
${ }^{12}$ Ibidem.

${ }^{13}$ Análises detalhadas e exemplos constam no texto "Resonancias discursivas y cortesía em prácticas de lecto-escritura", que publiquei na revista D.E.L.T.A, v. 17, n.1, em 2001.
} 
foco esteja no ensino e prática de diferentes funções comunicativas (tais como advertir, pedir, aconselhar, cobrar, agradecer, propor, etc.), para uma mesma construção lingüística (por exemplo, uma estrutura condicional). Isto, pode ser esclarecedor no nível da representação intencional, mas parece não bastar. Muitas vezes, o aprendiz conhece a relação entre essas funções e as construções que permitem formulá-las, mas igualmente fica calado ou muito confuso ao ser solicitado a produzir em contextos autênticos fora da sala de aula. Questões como essas levam a se interrogar mais profundamente sobre o processo de aquisição de segunda língua.

Talvez, a expressão 'aquisição de segunda língua' não seja a mais adequada para designar o processo de produzir e compreender em línguas não maternas. Ela acabou confirmada pelo uso para estabelecer distinções disciplinares, editoriais, departamentais (em instituições de ensino ou pesquisa) e assim por diante. Entretanto, seu uso parece-me adequado somente se ficar esclarecido que a produção lingüístico-discursiva em segundas línguas não resulta de algo meramente adquirido do exterior. Não se trata de um processo fosse de estocagem de palavras e de regras de combinação por um sujeito que, estando separado da língua, a adquire. Sujeito, língua e discursividade estão imbricados substancialmente. A linguagem é recebida por um sujeito, sim, do exterior. Mas, no processo de enunciar, exterior e interior são instâncias distinguíveis mas não separáveis. No processo de tomar a palavra para produzir sentidos há muito mais a levar em conta do que léxico e sistema da língua. Como bem mostraram Jakobson e Pêcheux ${ }^{14}$, em toda produção verbal de sentido operam processos discursivos básicos, como os metafóricos e os metonímicos. ${ }^{15}$

Com a finalidade de evidenciar como operam esses processos na aquisição de linguagem, referirei um exemplo que colhi observando uma criança (G.) em fase de aquisição de linguagem. Em uma ocasião, ao estar G. em uma reunião social com adultos, quando foram servidas cerejas cristalizadas, G, que não conhecia a palavra "cereja", apontou em direção a elas e disse: “"Quero pepel!". Coube interrogar-se: porque "pepel” (papel) para nomear as cerejas? A explicação para tão inusitada expressão veio das seguintes vivências discursivas de G: Quase sempre que G. comia balas, elas lhe eram entregues pela avó, que era também quem as levava à casa de G. No momento da entrega de uma bala, costumava haver diálogos entre a avó e G., nos quais ela enfatizava o fato de ser preciso "tirar bem o papel, mesmo que esteja grudado". Nessas ocasiões a avó repetia enunciados como: "Muito bem! Tirou todo o papel!", "O que tem que tirar?",

\footnotetext{
${ }^{14}$ Ver. Jakobson, N. 1969, p. 61-67 e Pêcheux, M. 1988, p. 164-168.

${ }^{15}$ Nos estudos de aquisição de linguagem, esses processos vem sendo estudados sistematicamente por Cláudia Lemos. Ver, por exemplo, o trabalho da autora publicado em 1991.
} 
"Muito bem! Pode comer, não tem mais papel!". No episódio com as cerejas, quando G. precisou de novo léxico, funcionaram processos metafóricos e metonímicos. As qualidades de doçura, tamanho pequeno, forma arredondada, e cor brilhante foram transpostas (metaforicamente) por ele da bala à cereja. E ao utilizar a palavra destacada na experiência socialdiscursiva com balas, trata-se do nome de parte (metonímia) do objeto doce que a avó entregava. O exemplo ilustra como os jogos semânticos de relações entre parte e todo, bem como as comparações, que levam ao uso de uma palavra por outra, são processos discursivos básicos na aquisição de linguagem.

A preocupação com o fato de o aprendiz de língua não materna desconhecer léxico e estruturas morfossintáticas da língua alvo parece reforçar a postura que privilegia o saber lingüístico, no que diz respeito à lógica do enunciado. Mas sem enunciação não há enunciado. A língua não preexiste o discurso. Ela acontece sempre em gêneros discursivos ${ }^{16}$, inscritos em processos sócio-históricos de significação. Na verdade, aprendemse discursos, para cuja realização é indispensável a língua que, por sua vez, pode acontecer somente em discursos. O léxico, a fonologia e as estruturas morfossintáticas são concomitantes com a dimensão discursiva. Há, sim, como dizem Pêcheux e Fuchs ${ }^{17}$, condições materiais de base, sem as quais a produção verbal de sentidos não é possível, mas elas são lingüísticas e históricas. Na visão do processo discursivo, toda seqüência resulta de domínios de memória, está vinculada a uma rede de seqüências coexistentes (domínio de atualidade) e aponta a novas formulações (domínio de antecipação) ${ }^{18}$. Na aprendizagem de uma língua estrangeira há um momento em que aparece com maior evidência a operação de nomeação. Mas ela é sempre, simultaneamente, uma predicação, um modo de situar aquilo que está sendo nomeado em uma rede de valores e sentidos vinculados diretamente a vivências e memórias discursivas.

Essa rede de valores e sentidos, na perspectiva da Análise de Discurso, é entendida como rede de formações discursivas. Conforme a definição clássica, essas formações indicam o que pode (ou deve) ser dito a partir de uma dada posição em uma conjuntura sócio-histórica determina$\mathrm{da}^{19}$. A noção de formação discursiva foi sempre relevante na Análise de Discurso (AD) para compreender que as palavras não significam «em si», mas seu sentido depende da posição a partir da qual são produzidas em um

\footnotetext{
${ }^{16}$ A concepção de enunciado e os trabalhos de Bakhtin (ed. 1988) sobre os gêneros discursivos foram precursores e inspiradores de muitos estudos do discurso desenvolvidos posteriormente.

${ }^{17}$ Cf. Pêcheux e Fuchs in Pêcheux, 1990.

${ }^{18}$ Cf. J. J. Courtine, 1981.

${ }^{19}$ Cf. Haroche, Henry, Pêcheux, in Pêcheux, 1990.
} 
contexto dado (condições de produção do discurso). Entretanto, ao longo do desenvolvimento da teoria, a conceituação de formação discursiva teve evoluções. Nos primórdios da AD, essas formações eram entendidas como espaços discursivos fechados, constituídos a partir de posições políticoideológicas homogêneas e excludentes. Isso levou a configurações esquemáticas e a que fossem consideradas como pontos de partida e não de chegada na análise (como se entende atualmente). Os corpora eram coletados a partir de formações discursivas, tais como as "operárias» ou "patronais», sem nuances ou contradições no interior delas. Atualmente, as formações discursivas são entendidas como condensações de regularidades enunciativas que, não por serem espaços de reformulação-paráfrase com tendências de visões de mundo predominantes, deixam de ser espaços heterogêneos e contraditórios neles "mesmos". Dessa forma, é possível analisar alteridades que constituem (contraditoriamente) dominâncias enunciativas em uma dada formação discursiva, mesmo que esse outro nunca seja mencionado explicitamente. Por exemplo, em uma formação discursiva caracterizada pelo predomínio de sentidos racistas, a raça que causa o discurso, pode não ser jamais mencionada explicitamente, mas a análise pode evidenciar sua presença constitutiva no discurso em questão.

A relevância da noção de formação discursiva e o desafio que ela introduz em contexto educativo impõem, apesar da finalidade teórica do artigo, algumas observações sobre sua implementação. O que interessa nas práticas é propiciar a sensibilização a diferenças enunciativas na construção de discursos, que a concepção de formação discursiva contribui teoricamente a compreender. Assim, não é preciso haver, no âmbito da prática em aulas de línguas, discussões conceituais ou atividades metalingüísticas dedicadas explicitamente ao uso da noção. Essa discussão corresponde ao âmbito dos princípios teóricos fundamentais. Eles devem estar articulados às propostas didáticas, mas cada âmbito tem sua especificidade. Uma forma de implementação que pesquisamos ao elaborar propostas pré-pedagógicas para aulas de leitura em língua estrangeira ${ }^{20}$ é o trabalho sistemático com a intertextualidade explícita. Em estudos de caso, foram avaliadas técnicas para propiciar o desenvolvimento da sensibilidade a diferentes modos enunciativos. Uma das formas avaliadas positivamente consiste em propiciar que as práticas em sala de aula estejam vinculadas ao trabalho

${ }^{20}$ Trata-se de trabalhos do Grupo de Pesquisa (CNPq) "Gêneros Discursivos no Hispanismo e no Plurilingüismo" sediado no IEL-UNICAMP. Resultados de pesquisa constam, por exemplo, nos artigos "Uma Análise Pré-Pedagógica de Textos Baseada na Concepção Discursiva da Linguagem" e "Discurso sobre a Textualidade e Línguas Estrangeiras Próximas" que publiquei em Trabalhos em Lingüística Aplicada, 2, 1983 e Anais da Anpoll, 2000, respectivamente, ou no trabalho de Baghin-Spinelli, D. "Uma Proposta Discursiva de Leitura nos Cursos de Formação de Professores de Língua Inglesa”, Fragmentos 22, UFSC, Florianópolis, 2002. 
conjunto de vários textos (escritos ou orais) de um mesmo gênero discursivo e sobre um mesmo assunto. Por exemplo, em um dos casos pesquisados, foi feita a análise discursiva de três textos do gênero editorial do discurso de divulgação científica, publicados nas revistas Science, Nature e New Scientist ${ }^{21}$, previstos para aulas de leitura em inglês para estudantes universitários de Biologia, Química e Engenharia Química. Os três textos tratam do debate sobre dedicação de igual tempo ao criacionismo e ao evolucionismo para explicar as origens do universo, nas aulas de ciência nas escolas americanas. Nas análises propostas, os textos são concebidos como unidades pragmático-discursivas de significação e não apenas como unidades empíricas definidas pelo começo meio e fim da sequiência linear. Assim, as condições de produção do discurso são fundamentais na análise. Elas dizem respeito à pesquisa sobre as fontes e a representação que o próprio veículo faz de si e de seus leitores, por exemplo, nas mesmas revistas ao fazerem as próprias apresentações para a chamada de assinantes. Nesse sentido, convém expor algumas informações. Science destaca que é o órgão oficial da Associação Americana para o Avanço da Ciência. Nature é também uma das mais tradicionais revistas dirigidas à comunidade científica, mas trata-se de uma revista inglesa que na sua auto-representação enfatiza ser um órgão de opinião. New Scientist é destinada a um público mais amplo e jovem, e se define como revista de ciência mas também de tecnologia. As análises pré-pedagógicas permitem distinguir tipos de memórias discursivas mobilizadas para construir posições argumentativas nos textos. Isso é feito mediante o estudo do funcionamento textual das construções sintáticas e da caracterização discursiva da seleção lexical. Como ilustração, mencionarei apenas um traço saliente em cada texto para a produção discursiva de sentidos.

No texto de Science predominam frases curtas, de período simples, com modalizações lógicas e apreciativas escassas. Elas funcionam construindo um discurso categórico, com argumentos que mobilizam memórias do discurso científico, marcado pela exposição maciça de dados empíricos quantitativos sobre a idade da terra. Exemplo:

"In the dating of ancient materials the best values are obtained by radiometric methods. Al least five independent ra-

\footnotetext{
${ }^{21}$ A pesquisa inicial considerou os editoriais: "Creationism and the Age of the Earth", "Creationists and Science in Schools" and "The Creation of an Evolving Theory", publicados em Science, v. 215 de 08/01/82 e em Nature e New Scientist, ambas de 14/01/82. Em diferentes implementações desses resultados foram incluídos materiais e recursos atualizados e ampliados. Recentemente, por exemplo, foi indicada pesquisa na Internet e os alunos visitaram os seguintes sites da BBC e da ABCNews, com textos sobre o tema: http:// news.bbc.co.uk.1/hi/education/1896164.stm e http://abcnews.go.com/sections/us/ TakingSides/takingsides $2 . h t m l$.
} 
dioisotope clocks have been employed. (...) Data from geology, geochemistry, and geophysics all testify that the age of the earth is much greater than 10000 years. For example, geologists have encountered a large number of formations in which the total number of annually deposited layers far exceeds 10000 . Geochemists have studied the decomposition of organic matter to form petroleum. Laboratory studies show that the rate of decomposition is such as to require millions of years to release the hydrocarbons found". ("Creationism and The Age of the Earth", Science, v. 215, n. 4529).

No texto da Nature prevalecem sentenças longas, com presença de abundante subordinação, com a característica de muitas delas estarem na forma interrogativa (em alguns casos, perguntas retóricas que constroem sentidos de indignação do autor), para construir argumentos baseados, também, em memórias do discurso científico. Mas a ênfase está no enfoque qualitativo dos resultados de pesquisa, ao mobilizar memórias em que ciência e educação estão estreitamente ligadas. Exemplo:

"By what logic can it be held that because Darwinism is unfalsifiable in some technical (and disputed) sense, a set of hypotheses which is in the same sense falsifiable and amply falsified should be given equal time in the curriculum of the public schools of Arkansas and elsewhere? (...) Other educational questions remain. (...) Or is it thought, in Arkansas and elsewhere, that the teaching of science consists of the recitation of facts by teachers and feats of memory by students? (...) For that matter, should the history of the world outside the Americas continue to be considered suitable only for colleges and universities? (...) School boards throughout the United States should not think that Judge Overton's judgement [against creationism in schools] is an all-round endorsement of the present curriculum". ("Creationists and Science in Schools", Nature, v. 295, p. 85).

O texto de New Scientist se caracteriza pela inclusão de léxico de diferentes registros, pela mobilização de memórias da filosofia da ciência e pela interrogação explícita em relação a memórias discursivas das ciências humanas. Exemplo:

"If you are not a specialist, and thus are not party to the details of the current arguments and to their nuances, you could easily assume that biologists doubt the fact of evolution; and if you have a vested interest in throwing doubt on Darwin, then you can readily fan such venial assumptions into a belief that something is indeed rotten in the state of biology. (...) Some creationists are stupid -just as some scientists are stupid- but many are not. Those that are not can hardly fail to see 
that a literal "fundamentalist" acceptance of the Bible is difficult to entertain (...). Why creationism? Is a question to which we invite scientists, perhaps in the form of psychologists or anthropologists, to provide an answer". ("The Creation of an Evolving Theory", New Scientist, v.94, p. 58).

Em relação ao pressuposto da noção de formação discursiva nas análises, cabe comentar que ele permite superar a abordagem da argumentação "a favor" ou "contra" um determinado assunto. Neste caso, os três textos argumentam contra o criacionismo, mas a partir de perspectivas e regularidades enunciativas que se encontram em diferentes relações de contradição entre si. As contradições, conforme Foucault (1986), podem ser intrínsecas, derivadas ou extrínsecas. Nas primeiras, há diferenças no nível das proposições mas os sentidos construídos tendem à coincidência ou à complementaridade. Quando a relação é de contradição derivada, há oposição visível no nível das proposições, mas o regime enunciativo não chega a ser antagônico (geralmente se trata de diferentes estratégias discursivas para construir sentidos aliados). No caso de formações discursivas relacionadas por contradições extrínsecas, tanto as formulações são opostas quanto os sentidos construídos no discurso encontram-se em posições irredutivelmente antagônicas. No caso que está sendo comentado, os resultados da análise pré-pedagógica de base discursiva indicaram a pertinência de se trabalhar com a hipótese de três formações discursivas: uma quantitativista e outra de enfoque qualitativo no discurso de divulgação científica, que estariam, entre si, em relação de contradição intrínseca; e uma terceira formação discursiva não cientificista, em relação de contradição derivada com as duas anteriores. Assim, tendo esses pressupostos teóricos, a prática de compreensão em sala de aula não pode ser concebida como mera decodificação. E as práticas de produção enfatizarão a sensibilização às nuances enunciativo-argumentativas na construção discursiva do aprendiz. Isso será somente possível mediante a mobilização de processos identificatórios - do professor e do aluno - ao compreender e ao tomar a palavra assumindo posições de sentido na produção discursiva em língua alvo.

Aprender significativamente novas línguas indo além do poliglotismo que supõe uma mesma realidade universal a ser recodificada em diferentes línguas acarreta a consideração de identificações ideológicas e subjetivas. Esse tipo de aprendizagem não decorre apenas da inclusão de novas informações ou conhecimentos. Ela implica em desarranjos e re-arranjos subjetivo-emocionais, cognitivos e sociais, para os quais é preciso estar-se pronto para experiências de (próprio) estranhamento. Estas possibilitarão que haja, por processos identificatórios ou desidentificatórios, 
novas inscrições subjetivas em discursos, mais especificamente em formações discursivas, da segunda língua-cultura. Os estudos que consideram a hipótese do inconsciente no estudo da subjetividade mostram que a língua materna e suas memórias discursivas são as que dão as cartas. Mas estas podem não ser todas as cartas desejadas por um sujeito e suas relações com memórias discursivas de novas línguas e culturas podem fornecer outras, para jogos novos ou para jogar os já conhecidos de uma outra maneira. Essas relações e eventuais identificações (particularmente as imaginárias) acontecem no tempo e são ligadas diretamente à materialidade lingüística. Existem, assim, evoluções, retrocessos, progressos ou estancamentos no desempenho lingüístico-discursivo, que podem ser constatados e descritos. No entanto, é preciso que essa descrição não seja apenas lingüística. Por exemplo, ao considerar-se a representação do aspecto instrumental das línguas, observa-se que um locutor-aprendiz, em um momento, poderá somente cumprimentar na língua alvo e, em outro, encomendar uma refeição ou discutir com o garçom sobre preferências e preços de pratos. Mas isso não está desvinculado da observação dos lugares e posições sociais dos protagonistas do discurso. Será que as condições de produção permitem que essa discussão de preferências gastronômicas possa existir? O cliente é estrangeiro? Que tipo de estrangeiro ele/a é e qual é a sociedade de origem e qual o contexto do encontro? Quais memórias discursivas há na sociedade em questão para os dizeres de um garçom? Por exemplo, em determinadas sociedades, essas memórias autorizam que ele exponha ou mesmo "imponha" suas sugestões, em outras sociedades as memórias discursivas, socialmente construídas, não possibilitam isso, e o garçom "deve" servir silenciosamente. Também, é preciso analisar componentes das formações discursivas desses protagonistas, que incluem a consideração das classes sociais de ambos, mas não apenas isso. Em uma "mesma" classe social há posições enunciativo-ideológicas diferentes. Esse é um dos pontos em que a Análise do Discurso se diferencia de outras áreas dos estudos da linguagem que também consideram a dimensão social, como por exemplo a Sociolingüística laboviana. Vemos, assim, porque a língua não pode ser concebida como um mero instrumento, que o sujeito "dominará", pautado por progressões de complexidade gramatical ou de situações "comunicativas". Falar, ou melhor, enunciar significativamente é sempre um processo cuja complexidade estrutural supera o mero exercício de habilidades para "comunicar mensagens" ou satisfazer "necessidades" imediatas. Enunciar em outras línguas diz respeito à constituição identitária do sujeito, composta dinamicamente por memórias discursivas contraditórias. 


\section{CONSIDERAÇÕES FINAIS}

Para finalizar, gostaria de lançar uma interrogação sobre uma certa mitificação da "responsabilidade" do professor de línguas pela "integração" dos aprendizes em uma nova língua-cultura. A consideração de memórias discursivas e de processos identificatórios leva a questionar o mito da onipotência e o normativismo existentes com certa freqüência em projetos pedagógicos concernentes a segundas línguas. Na relação com línguas não maternas, há dimensões de ação que dependem de decisões ou julgamentos voluntários de alunos e professores. Contudo, o intercultural mobiliza sempre dimensões subjetivas que não dependem totalmente da vontade consciente. Isso não significa, porém, que não haja nada a se fazer nesse domínio. Considerar especialmente a existência do componente inconsciente estando-se atento aos seus indícios indiretos pode permitir ampliar a conscientização sobre seu funcionamento e seus efeitos e, eventualmente, transformá-los. Boa parte do papel crucial que o ensino de línguas pode cumprir na educação integral do cidadão decorre dos desafios subjetivo-identitários que a consideração das memórias discursivas põe em evidência.

\section{BIBLIOGRAFIA}

AUTHIER REVUZ, Jacqueline. Ces mots qui ne vont pas de soi. Boucles réflexives et non coüncidences du dire. Paris, Larousse, 1995.

BAKHTINE, Mikhaïl. Esthétique de la création verbale. Paris, Gallimard, 1988. Trad. Alfreda Aucouturier. Estética da Criação Verbal. São Paulo, Martins Fontes, 1992.

BONNET, M. F. Lien social et passage de langues. In : GODELIER, M. e HASSOUN, J. J. (orgs.). Meurtre du père sacrifice de la sexualité; Approches anthropologiques et psychanalytiques. Strasburgo, Arcanes, 1996. p.131-146.

CALLIGARIS, Contardo. Sociedade e Indivíduo. In: FLEIG, M. (org). Psicanálise e Sintoma Social. São Leopoldo, Unisinos, 1997.

COURTINE, Jean-Jacques. Analyse du discours politique. Paris, Larousse, Langages, n. 62, juin. 1981.

FOUCAULT, Michel. La Arqueología del Saber. México, Siglo XXI, 1986. JAKOBSON, Roman. Essais de lingüistique générale. Paris, Éd. de Minuit, 1966. 
KRAMSCH, Claire. Context and Culture in Language Teaching. Oxford, Oxford University Press, 1996.

KRISTEVA, Julia. Étrangers à nous mêmes. Paris, Gallimard, 1991.

LEMOS, Cláudia. Los procesos metafóricos y metonímicos como mecanismo de cambio. Barcelona, Substratum 1, p.121-135.

MANNONI, O. A desidentificação. In: MANNONI, M. As Identificações na Clínica e na Teoria Psicanalítica. Rio de Janeiro, Relume Dumará,1994.

NASIO, Juan. Os 7 Conceitos Cruciais da Psicanálise. Rio de Janeiro, Zahar, 1995.

ORLANDI, Eni. A linguagem e seu Funcionamento. As formas do discurso. São Paulo, Brasiliense, 1983.

. Interpretação. Petrópolis, Vozes, 1996.

PÊCHEUX, M Semântica e Discurso. Uma Crítica à Afirmação do Óbvio. Campinas, Ed. da Unicamp, 1988.

. L'Inquiétude du discours. Textos de M. Pêcheux escolhidos e apresentados por M. Maldidier. Paris, Éd. des Cendres, 1990.

. Mises au point et perspectives à propos de l'analyse du discours. In: PÊCHEUX, M. L'Inquiétude du discours. Paris, Éd. de Cendres. Trad. Bras.: GADET, F. e T. HAK (org). Introdução à Análise Automática do Discurso. Campinas, Ed. da Unicamp, 1990.

REVUZ, Christine. A língua estrangeira entre o desejo de um outro lugar e o risco do exílio. Trad.: Silvana Serrani. In: SIGNORINI, I. (org.). Lingua(gem) e identidade. Campinas, Mercado de Letras, 1998.

SOUZA, Otávio. Fantasia do Brasil. As Identificações em Busca da Identidade Nacional. São Paulo, Escuta, 1994.

STERN, David. Seeing the wood AND the trees: some thoughts on language teaching analysis. In: JOHNSON, R. K. The Second

Language Curriculum. Cambridge, Cambridge University Press, 1989.

TODOROV, Tzvetan. Nous et les autres. Paris, Éd. du Seuil, 1988. 